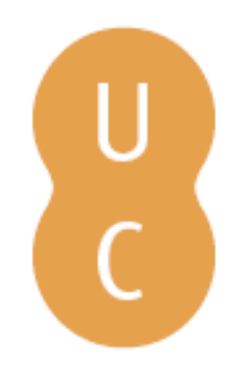

\title{
pompalina
}

\section{Cultura material y consumo entre la élite universitaria vallisoletana en el siglo XIX}

Autor(es): Dávila Corona, Rosa María

Publicado por: Imprensa da Universidade de Coimbra

URL

persistente: URI:http://hdl.handle.net/10316.2/31588

DOI: $\quad$ DOI:http://dx.doi.org/10.14195/978-989-26-0201-1_9

Accessed : $\quad$ 26-Apr-2023 11:27:51

A navegação consulta e descarregamento dos títulos inseridos nas Bibliotecas Digitais UC Digitalis, UC Pombalina e UC Impactum, pressupõem a aceitação plena e sem reservas dos Termos e Condições de Uso destas Bibliotecas Digitais, disponíveis em https://digitalis.uc.pt/pt-pt/termos.

Conforme exposto nos referidos Termos e Condições de Uso, o descarregamento de títulos de acesso restrito requer uma licença válida de autorização devendo o utilizador aceder ao(s) documento(s) a partir de um endereço de IP da instituição detentora da supramencionada licença.

Ao utilizador é apenas permitido o descarregamento para uso pessoal, pelo que o emprego do(s) título(s) descarregado(s) para outro fim, designadamente comercial, carece de autorização do respetivo autor ou editor da obra.

Na medida em que todas as obras da UC Digitalis se encontram protegidas pelo Código do Direito de Autor e Direitos Conexos e demais legislação aplicável, toda a cópia, parcial ou total, deste documento, nos casos em que é legalmente admitida, deverá conter ou fazer-se acompanhar por este aviso.

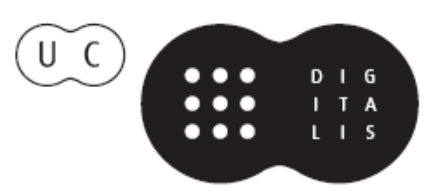


Isabel dos Guimarães Sá Máximo García Fernández (directores)

\section{PORTAS ADENTRO comer, vestir, habitar} (ss. XVI-XIX) 


\title{
CULTURA MATERIAL Y CONSUMO ENTRE LA ÉLITE UNIVERSITARIA VALLISOLETANA EN EL SIGLO XIX
}

\author{
Rosa María Dávila Corona \\ Departamento de Historia Económica ${ }^{1}$ \\ Universidad de Valladolid (España)
}

\section{ALGUNAS CONSIDERACIONES METODOLÓGICAS PREVIAS}

Una de las vías empleadas para aproximarse a la cultura material y al consumo de las élites universitarias vallisoletanas son los inventarios post mortem, mediante los que se nos muestra la esfera de lo domestico, de lo privado, del consumo realizado por la familia y el mundo cultural del profesorado. Hay que tener presente que estas relaciones de bienes responden siempre al planteamiento de cuestiones de herencia, especialmente en las minorías de edad, en que es necesario el nombramiento de tutores o curadores que miren por sus intereses. Para el fin propuesto, y para obtener una imagen más fiel de la cultura material de esta élite del saber, hemos escogido una muestra de 12 inventarios universitarios, contrastándolos con los de la burguesía de los negocios vallisoletana, en especial comerciantes, y con la clase burguesa propietaria de bienes inmuebles, cuya cronología comprende desde el final de los años 1830 hasta mediados de 1870.

No obstante, con ser, a falta de otras fuentes, la línea fundamental que nos permita acercarnos al mundo familiar docente, esta vía de conocimiento tiene una serie de limitaciones, derivadas del criterio, no siempre fijo, del tasador

${ }^{1}$ Este trabajo se inscribe dentro del Proyecto de Investigación, financiado por la Junta de Castilla y León (referencia VA049A08), titulado Cultura material, consumo, moda e identidades sociales. Mujer, vestido y apariencia en Castilla y en León durante el Antiguo Régimen (siglos $X V I-X I X)$. 
encargado de la peritación de los bienes, entre los que siempre figuran, aunque no forma de manera ordenada, las prendas que componen la imagen personal del profesorado y de su familia, el confort de la casa, visible a través de la ropa de casa y del mobiliario, y de un capítulo que nunca falta, por escaso que sea éste, como son las alhajas ${ }^{2}$. La variación del criterio empleado en la confección de los inventarios impide establecer unas pautas fijas que nos acerquen con cierta fiabilidad a la imagen personal, al confort y distribución de la vivienda, ya que en muchos de ellos inventarios no se incluye, por expreso deseo de la viuda, la ropa de vestir femenina. En dos de ellos tampoco aparece reflejada la indumentaria del profesor difunto, aunque es posible que fuera transmitida a sus herederos varones, o tal vez, pero no consta en los inventarios analizados, vendida, al no haberlos, por la viuda en almoneda. Tampoco se realiza una catalogación de los bienes familiares de acuerdo con la habitación donde están depositados, lo que menoscaba el conocimiento del interior y distribución de la vivienda y de sus partes más nobles. Salvo en dos casos, los de los profesores de Medicina y de Lengua Griega, Fernández Pérez y Alonso Ortega ${ }^{3}$, en que se describen los bienes de acuerdo a la posición que ocupan en las diferentes habitaciones de la casa, lo normal es que los inventarios presenten las lista de los bienes que componen el ajuar doméstico agrupados en grandes apartados como la ropa de vestir y de casa, el mobiliario, los efectos de cocina y las alhajas. E incluso, en lo que atañe a la esfera de lo cultural como es el despacho de trabajo del profesorado y su biblioteca, hay carencias bastante notables que se centran en la falta de descripción del mobiliario que compone este espacio dedicado al estudio y en la ausencia de la biblioteca y de los volúmenes contenidos en ella, vendidas en almoneda por expreso deseo de los herederos, y posteriormente contabilizado su importe en dinero entre los demás bienes del difunto ${ }^{4}$. En otros casos, se conoce el contenido, más o menos exacto de la biblioteca, gracias al reparto equitativo en volúmenes y su correspondiente valor monetario entre los hijos ${ }^{5}$. Todas estas limitaciones sólo permiten un acercamiento limitado a la imagen y la cultura material de esta élite universitaria vallisoletana en el siglo XIX, aunque puede ser suficiente para dejar en el aire algunas hipótesis.

${ }^{2}$ La lista normal que presentan los inventarios a la hora de catalogar los diversos bienes que integran el ajuar doméstico son, salvo en algunos casos, los siguientes: Ropa blanca, de mesa y de vestir, segregando en ocasiones, en este capítulo las ropas de vestir del difunto; muebles y maderas; loza y cristal y efectos de hierro -a veces efectos de cocina-; y libros.

${ }^{3}$ Archivo Histórico Provincial de Valladolid (Desde ahora AHPV), Protocolos Notariales, Legajos 16.408 y 16.531 .

${ }^{4}$ Son los casos de do catedráticos, uno de Teología Moral, el otro de Historia Universal y de un profesor de la Facultad de Medicina, cuyos libros junto con los armarios y librerías que los contenían fueron vendidos por los herederos. AHPV, Protocolos Notariales. Legajos 15.880, 16.284 y 19.034 .

${ }^{5}$ AHPV, Protocolos Notariales. Legajo 16.622. 
El cambio de régimen político y las transformaciones sociales operadas en el país y, como no en la ciudad de Valladolid, donde, además se produce un periodo de crecimiento económico desde los años 1840, puso en primera línea unos nuevos valores, los de la naciente burguesía, que impregnaran, progresivamente al resto de las capas de la ciudad. El profesorado, como parte de la burguesía, en su condición de reserva del saber y de la cultura, participó plenamente de los mismos, adoptándolos en su apariencia, en su ideología de cariz conservador ${ }^{6}$-constatable por los volúmenes catalogados en algunas de la bibliotecas conservadas en los inventarios, y en la forma de vivir, centrada en el hogar y en el confort que poco a poco fue adquiriendo.

La imagen del profesorado dentro del aula universitaria quedó fijada, en cada momento, por la correspondiente legislación en esta materia, que marcaba para la asistencia al recinto universitario primero, a principios de siglo XIX, los hábitos, y más tarde, a partir de los años cincuenta, la toga negra que cubría, obligatoriamente, el traje de calle usado por el docente ${ }^{7}$. Esta imagen sobria y, a la vez oscura, que indicaba el respeto, el decoro y la sobriedad, tiene su correspondencia con la que, bajo esos mismos parámetros, ofrece el docente dentro de la sociedad.

Una de las principales carencias que presenta la fuente utilizada para este tipo análisis es la falta de atención que se presta a la descripción no sólo de la ropa de vestir, y en menor medida de la de casa, sino en general a los bienes que componen el resto del ajuar doméstico. Quizás, una posible explicación para esta forma de actuar del tasador esté en el interés mostrado por la familia en el valor final de los distintos bienes que componen la herencia, y que, más tarde, deberían ser repartidos entre los distintos miembros. En este sentido es también sorprendente que, habiendo hijos menores de edad, e incluso niños pequeños, sus ropas casi nunca aparezcan en las relaciones efectuadas, salvo en dos casos en que se mencionan intercaladas entre las ropas del difunto profesor alguna mantilla de envolver, gorritos de niño y un faldón de cristianar ${ }^{8}$. Y lo mismo ocurre con el mobiliario que podrían utilizar, recogiéndose en sólo caso la existencia de cunas 9 .

Llama asimismo la atención el poco interés por la ropa interior masculina que, en dos inventarios es totalmente inexistente ${ }^{10}$, y lo mismo se podría decir

${ }^{6}$ Rosa M ${ }^{a}$ Dávila Corona, «La apariencia y el saber: vestimenta y lecturas del profesorado universitario vallisoletano en el siglo XIX», en Derecho, Historia y Universidades. Estudios dedicados a Mariano Peset, vol. I, Valencia, Universidad de Valencia, 2007.

${ }^{7}$ Rosa $\mathrm{M}^{\mathrm{a}}$ Dávila Corona, «Algunos aspectos de la vida universitaria vallisoletana del siglo XIX (1800-1880)», en Aulas y Saberes. VI Congresso Internacional de Historia de las Universidades Hispânicas (Valencia, 1999), Valencia, Universidad de Valencia, 2003, pp. 347-362.

${ }^{8}$ AHPV, Protocolos Notariales. Legajo 15.882.

${ }^{9}$ AHPV, Protocolos Notariales. Legajo 16.284.

${ }^{10}$ AHPV, Protocolos Notariales. Legajos 15.934 y 16.497. 
respecto a la ropa de vestir, enumerada de forma muy parca, como en el caso del profesor de Medicina Junquera, en el que por ejemplo sólo se mencionan cuatro chalecos, tres pantalones y un gabán como únicas prendas de vestir masculinas $\mathrm{y}$, que desde luego, tenían que estar muy lejos de las existentes en la realidad cotidiana ${ }^{11}$. En ambos casos, la relación de las prendas -interiores y exterioresque se catalogan se reduce únicamente al nombre de la pieza, a veces al color, $\mathrm{y}$, en ocasiones, al estado de conservación, no siendo este último aspecto un hecho habitual continuado en todos y cada uno de los inventarios. En el más afortunado de los casos, a veces, se incluye algún detalle, sobre todo al inventariar las capas, como los cuellos de terciopelo y las cadenitas para abrocharla, siempre y en todos los casos en que se recogen, tasadas con el mayor precio respecto al resto de la ropa, diferenciándolas y cualificándolas como prenda de mayor calidad que el resto.

Posiblemente haya que atribuir esta simplicidad de datos a la intención del tasador que realiza el inventario y a la de la propia familia por reflejar únicamente el valor material de todo el ajuar doméstico. Por eso, en la relación, más que a la forma de la prenda, se pone más énfasis en la tela en que esta confeccionada, pues según la clase y calidad que ésta tenga su influencia sobre el precio será mayor, luego al estado de conservación de la misma, al color, ya que en ocasiones éste revaloriza la pieza, y, ocasionalmente, a la presencia de algún detalle especial que la ornamente y la aprecie, como son los bordados, los cuellos forrados con telas caras, los bozos de terciopelo que adornan los cuellos de las capas, las cadenas u otros broches que la sujetan al cuello, las botonaduras de hueso, nácar o de metal dorado, etc.

\section{LA SOBRIEDAD EN LA APARIENCIA PERSONAL DE LA ÉLITE UNI- VERSITARIA}

El ajuar representa dentro del patrimonio del profesorado un porcentaje que va en algunos casos del 79\% al 7\%, siendo el resto para los demás bienes del ajuar, dinero en metálico, bienes inmuebles y raíces de los que eran en su mayoría propietarios. Ahora bien, sobre el ajuar, el porcentaje medio que representa la ropa de vestir, la ropa interior y los complementos utilizados supone algo menos que el dedicado a la ropa de casa y a al capítulo de las alhajas, (ambos con el 21,5 y $21,6 \%$ respectivamente), pero inferior al que presentan los comerciantes del ramo del textil, que supone un $23,7 \%$. En cuanto la tasación de las denominadas en los inventarios alhajas, se comprende en ella todo tipo de objetos fabricados en metales preciosos -sortijas, crucifijos, collares, cadenas de oro, pendientes, etc.- incluyendo los cubiertos de mesa normalmente de plata. Esta diferencia tan

${ }^{11}$ AHPV, Protocolos Notariales. Legajo 16.622. 
pequeña entre la apariencia, el adorno de la misma y el confort y lujo de la casa, supone que el profesorado concedía el mismo grado de importancia a la imagen personal que a la comodidad del hogar de acuerdo al status social que representaba dentro de la sociedad burguesa vallisoletana.

Dentro de este porcentaje medio, el vestuario masculino del profesorado, en el que se comprenden los complementos del vestir, supone más del $60 \%$ de la ropa de vestir de la familia, dedicándose el resto al guardarropa femenino. Las preferencias del profesorado se inclinan hacia las prendas que conforman la imagen personal, llegando individualmente, en algunos casos, a ser superiores al $70 \%$ e incluso al $90 \%$. Por el contrario, la parte que se dedica a la ropa interior masculina se sitúa en torno al $15 \%$, aunque hay profesores que sobrepasan este porcentaje, elevándolo al $37,2 \%$, estando constituido fundamentalmente por calcetas, medias y alguna camisa. El consumo de complementos de vestir, como pueden ser las corbatas, los pañuelos, sombreros y zapatos, también es bastante reducido, situándose como media en el 7\%, aunque haya profesores que inviertan individualmente en esta parte del guardarropa el 20,8\%.

En los seis inventarios donde también aparece la ropa femenina, la proporción en el vestuario es algo diferente, ya que la ropa de vestir supone el $48 \%$ del guardarropa, seguido de las prendas que complementan y realzan, e incluso modifican la apariencia con un $43,3 \%$, mientras que las enaguas, chambras, justillos, medias, calcetas, etc., alcanzan, como en el caso de los profesores, una media muy pequeña respecto al resto de la ropa, que en este caso es del $9 \%$.

De las 1.069 piezas de vestir contabilizadas en total, 617 corresponden a prendas de vestir, de ropa interior masculina y complementos, y 452 en los mismos conceptos a las femeninas. En cuanto a las masculinas, sólo el 25\% aportan datos sobre su estado de conservación y sobre la calidad de la prenda, revelando que más de la mitad son usadas o muy usadas, un 10\% viejas y tan sólo un $12 \%$ nuevas, aunque no para estrenar. En cuanto a su calidad sólo el 13\% se consideran buenas, mientras que a un $8 \%$ se las califica de medianas. Algo muy similar ocurre con las femeninas. De las 452 piezas que componen los seis vestuarios, tan sólo el $23,2 \%$ ofrece datos sobre el estado de conservación y la calidad de las prendas. El 67,6\% de las mismas están conceptuadas como usadas, muy usadas, bastante usadas o andadas, el 7,6\% como en buen uso y, solamente el $12 \%$ se consideran nuevas, aunque como en el caso anterior, no para estrenar. Esta tónica en la clasificación de las prendas según su estado de conservación se mantiene para la burguesía comercial y propietaria, lo mismo que para los conjuntos de las dotes femeninas urbanas y rurales ${ }^{12}$.

${ }^{12}$ M. García Fernández y R. M ${ }^{a}$ Dávila Corona, «Vestirse y vestir la casa. El consumo de productos textiles en Valladolid (1700-1860)», en Obradoiro de Historia Moderna, vol. 14, 2005, pp. 141-174. 
Respecto a las telas que componen la ropa de vestir masculina, los lienzos, nacionales o extranjeros, los hilos y las mezclas de lana y algodón son las preferidas para las prendas de ropa interior, las camisas y los camisolines. El traje masculino se inclina para su confección por las telas de lana de diferentes calidades $^{13}$, normalmente en colores oscuros y lisos, relegándose los cuadros, en tamaño grande o pequeño, igualmente empleando colores apagados y sobrios, así como las rayas y alguna tela labrada menudamente para los pantalones. La seda, el terciopelo y el raso de colores claros como el blanco, las telas labradas y las estampadas, además de bordadas, se destinan a los chalecos, de los que se recogen en los inventarios 41 piezas, proporcionando, a la vez que un rasgo de elegancia, un toque de color y fantasía en una apariencia austera, caracterizada por ir evolucionando en sintonía con la moda del momento, pero dentro de las coordenadas marcadas por el espíritu de sobriedad y decoro de la burguesía. Sin embargo, hay que reseñar que, en comparación con el colorido empleado en la confección de esta prenda por otros grupos burgueses, como por ejemplo los comerciantes, donde los tonos, aun siendo oscuros, son más variados y vivos, el profesorado refleja un aspecto monocromo y más austero.

Posiblemente donde se registrasen los cambios más notables fuese en la moda masculina, siendo evidente entre las clases medias urbanas, a las que pertenecía el profesorado universitario. A la altura de 1840, las clásicas prendas usadas al comenzar el siglo como las casacas, los jubones y las chupas, etc., han sido sustituidas íntegramente por un nuevo modelo de traje masculino, compuesto, en ocasiones, por la chaqueta, la levita -y su variante la levita-gabán- que supone el $7,2 \%$ de las prendas inventariadas y que era usada en invierno y en verano en diferentes tipos de textiles adaptados a la estación; los chalecos representan el $15,7 \%$ del total de prendas de vestir masculinas, y los pantalones el 20\%, estando en este último caso el $22 \%$ catalogados como usados o bastante usados. La imagen de respetabilidad, aunada al deseo de pasar desapercibido ante los demás, se subraya con el colorido que impone la moda romántica a este propósito. Los colores utilizados en el traje, que se oculta debajo de la toga, nos dan una imagen oscura, de colores nada estridentes en los que domina el negro junto a los verdes y a los azules, y a otros tonos nuevos, también llenos de sobriedad como el «pasa», el «pizarra» y el «aplomado, que bajo el influjo de las primeras revistas de moda y maniquíes, se difunden y popularizan entre la burguesía, desde los escaparates comerciales.

${ }^{13}$ Las telas de lana abarcan una gran variedad, dominando los diferentes tipos de paños fuertes y finos, junto al alepín de la reina, los muletones, las lanillas, los merinos, los buratos, las cúbicas y el rúsel. Entre las telas de seda, están la propia seda, la felpa, el terciopelo, el satén, el raso y el punto de seda. Rosa $\mathrm{M}^{\mathrm{a}}$ Dávila, Montserrat Duran y Máximo García Fernández, Diccionario histórico de Telas y Tejidos Castellano-Catalán, Valladolid, Junta de Castilla y León, 2004. 
La chaqueta junto con la levita formaba la parte superior del atuendo masculino. La primera, generalmente de paño, franela o mahón, más corta que la otra, fue usada por el profesorado, lo mismo que por el resto de la burguesía, desde los años treinta hasta mediados de los cincuenta, para el vestir corriente durante la mañana debajo del hábito universitario primero, y después, a partir de 1850 , de la toga. De este tipo de prenda se contabilizan, entre los años treinta y cincuenta del siglo XIX ocho unidades, de las que el 50\% pertenecieron al catedrático de Teología Moral Melchor Rodríguez. Aunque la compartan como atuendo formal con otros grupos burgueses, como el de los comerciantes, sin embargo el colorido sigue siendo el que impone el deseo de respetabilidad, utilizando los tonos oscuros a diferencia de los usados por los empresarios del comercio que son más claros como los azules o los castañas. A partir de esa fecha comienza a ser reemplazada por otra prenda similar, con solapas que recibe el nombre de americana, y que será de uso común entre algunos profesores influidos tal vez por los escaparates de las sastrerías decorados con maniquíes vestidos con ella. Sin embargo, el porte elegante, de sobriedad, respetabilidad y autoridad le corresponderá a la levita, con la que la primera competirá durante el resto del siglo, hasta desterrarla por completo a principios del siglo XX.

La levita, prenda de vestir por excelencia de la élite burguesa política, social y profesional, era una prenda exterior, larga hasta las rodillas, abotonada y con solapas, confeccionada en paños y lanas de calidad como la alpaca y el patén, que utilizó una parte importante del cuerpo docente universitario tanto para asistir a las clases como para concurrir a las reuniones y otros actos de la vida social, dando una imagen de refinamiento gracias al uso de los corbatines y de las corbatas ${ }^{14}$. Para la etiqueta, en solemnidades y fiestas, será sustituida por el chaqué y el frac, prendas que, a pesar de ser indicadas en la etiqueta social de la época, no se encuentran en la misma cantidad que en el resto de los inventarios de los comerciantes y de los burgueses propietarios. El frac de paño en color negro, adornado con una corbata blanca, se convirtió, a partir de 1850 en el traje de etiqueta preceptivo que había que vestir debajo de la toga, para asistir a las ceremonias universitarias solemnes como la apertura de curso $^{15}$.

La tradicional prenda de vestir, la capa, adornada con cuellos de color azul o con bozos de terciopelo, competirá, en el vestuario docente, con nuevas prendas de abrigo mucho más cortas, de origen extranjero, que se harán de uso cotidiano, como el chaquetón, la levita-gabán y el propio gabán que será la prenda que vestirá por excelencia el profesorado desde la década de los años cincuenta

${ }^{14} \mathrm{La}$ levita y el frac van a representar durante esta etapa del siglo que analizamos la pertenencia a una élite cultural y censitaria, pudiendo referirse su uso a la democratización de la moda masculina. Rafael Serrano García, El fin del Antiguo Régimen (1808-1868), Cultura y vida cotidiana, Madrid, Síntesis, 2001.

${ }^{15}$ R. M ${ }^{a}$ Dávila Corona, ob. cit. 
sobre el traje, tanto en invierno como en verano. Completan el abrigo de la persona prendas como el paletó, abrigo de tres cuartos de largura, algo entallado, y el emperador y las tubinas que se vistieron en los años 70 .

Si el traje masculino reflejaba una apariencia de seriedad, diligencia y honorabilidad, el uso externo de una serie de complementos reforzaba esta imagen, aportando un toque de distinción. La necesidad de mantener el decoro en la imagen que se ofrecía, hacían necesario emplear una serie de piezas postizas que se ponían sobre la camisa, como eran los cuellos y los puños postizos, numerosos en los inventarios, y el camisolín, pieza rectangular de hilo planchado o lienzo, con cuello pero sin espalda, que, en ocasiones suplía a la propia camisa, o tapaba la suciedad de la parte delantera de la misma.

Toda una serie de complementos reforzaban la imagen señalada. Los pañuelos y las corbatas, prestaban un toque de color y de refinamiento, mientras que los sombreros daban buen tono, sobre todo los de copa alta, indicados para los actos sociales de etiqueta, aunque también usaron los de copa baja y desde los años sesenta, el sombrero hongo para la vida cotidiana. Este conjunto de prendas supone el 34\% de los complementos del vestir masculino, a los que se sumarían los paraguas, los zapatos y algunas botas. La mayoría de estas piezas son catalogadas por los tasadores como prendas usadas o muy usadas, siendo muy escasos y poco relevantes los considerados nuevos.

En el traje de vestir del profesorado universitario se combinan la apariencia de respetabilidad, propia de una élite cultural, con la austeridad como lo indican la utilización de numerosas prendas usadas y la poca presencia de las nuevas o a estrenar, características todas ellas que concuerdan con lo observado en este aspecto para otros grupos burgueses como los empresarios del comercio y los de las profesiones liberales como los abogados ${ }^{16}$.

Como en el guardarropa masculino, y en cuanto al número de piezas, en el femenino dominan -como en otros inventarios femeninos de la burguesía comercial y propietaria-, las prendas de ropa interior con el 53\%, aunque su valor monetario es bastante reducido. Le siguen en porcentaje las prendas dedicadas a la indumentaria exterior con el 30\%, superior al que dedican en este mismo capítulo las mujeres de la burguesía comercial ${ }^{17}$, que es del $12 \%$. Los complementos del vestir -como pañuelos, mantillas o manteletas- suponen el $31 \%$, superando en un punto al guardarropa, y siendo superior al que dedican en este aspecto las mujeres de la burguesía comercial.

Los cambios en el guardarropa femenino no son tan evidentes en las tasaciones como los que se aprecian en la apariencia masculina ${ }^{18}$, si bien es cierto

${ }^{16}$ Rosa M $M^{a}$ Dávila Corona y Máximo García Fernández, «El consumo de productos textiles en Valladolid, 1750-1850», Investigaciones Históricas, 2001, n. 21, pp. 133-184.

17 AHPV, Protocolos Notariales. Legajos 8.424, 12.030, 16.264, 16.284, 16.723 y 19.032.

${ }^{18}$ Rafael Serrano Garcia, ob. cit. 
que, han desaparecido del armario femenino una serie de prendas tradicionales como los guardapiés, los delantales, zagalejos y basquiñas, prendas que todavía se inventarían -aunque en poca cantidad- entre las mujeres de los comerciantes, sustituidas mayoritariamente por el vestido. Esta prenda de vestir, de la que es imposible seguir su evolución al compás de la moda, por no saber si constaba de dos piezas -cuerpo y falda o era de una sola, o los detalles de cintas o lazos que les adornaban-, dadas las escuetas referencias que en los inventarios se hace de ella, constituye el $38 \%$ del vestuario de las mujeres e hijas de los docentes, cifra bastante inferior a la alcanzada en las mujeres de la burguesía comercial, donde se eleva hasta el $70 \%$ del guardarropa, acompañada de otras prendas más modernas, que no se encuentran entre las mujeres del profesorado, como las faldas y los abrigos. Lo que sí dicen claramente las tasaciones es que el 23\% de los vestidos eran usados o muy usados, hallándose solamente doce nuevos. El resto del vestuario femenino lo componen las camisas, posiblemente aunque los inventarios no lo indican, decoradas con puntillas y bordados, alguna prenda más moderna como las blusas, las capas y los mantones.

En cuanto a las telas sobresalen las tradicionalmente usadas por la burguesía vallisoletana de estos años, con una amplia variedad las de lana y seda, acompañadas de algunas de algodón, para la confección de vestidos y capas. Así por ejemplo, las capas suelen estar hechas con paño fino, mientras que los mantones van en crespón, en gro, en seda y en raso. Estas mismas telas de seda se emplean en los vestidos junto al tafetán y el terciopelo. Junto a ellas aparecen algunos textiles más novedosos como las lanas sencillas y ligeras como la cúbica, la muselina de lana y el merino y las de algodón como la chaconada y el percal, desmontando la imagen de un vestuario femenino antiguo y limitado en cuanto al uso de textiles más modernos y a la moda ${ }^{19}$. Es más, posiblemente las reseñas de moda y ecos sociales de los periódicos locales se encargasen de difundir una imagen más moderna que la que proporcionan los inventarios ${ }^{20}$. En cuanto al colorido del vestuario sigue las mismas pautas que el masculino de colores oscu-

${ }^{19}$ Según las opiniones de un erudito local bastante alejadas de lo que muestran las relaciones de los inventarios, el lujo en el vestir femenino era desconocido ya que «las señoras con un traje de alepín de la reina, tela de lana que no se ve por el mundo, y uno de tafetán para las grandes celebraciones, estaban servidas. Un vestido de terciopelo habría sido una enormidad y el gro no era conocido». J. Ortega Zapata, Solaces de un vallisoletano setentón, Valladolid, Universidad de Valladolid, 1984.

${ }^{20}$ A mediados de siglo el periódico local recién aparecido, el Norte de Castilla, describía en sus ecos de sociedad las novedades de la moda femenina para los últimos días del mes de octubre, describiendo los adornos de los vestidos, los colores más indicados y los complementos aconsejados para cada momento. Igualmente, los anuncios de ese mismo periódico ofrecen nuevas prendas llegadas de París y utilizadas por las elegantes, como los miriñaques, los pantalones interiores etc. Rosa María Dávila Corona, «Las ventas a crédito en los comercios vallisoletanos. 1830-1870», Investigaciones Históricas, n. 27, 2007. 
ros como el negro, el verde, el «pasa», la «flor de romero», el «pizarra» y el azul, aunque iluminados con estampaciones de flores o de cuadros.

Dentro de las prendas que sirven para adornar, complementar y enriquecer el vestuario femenino, destacan, y más en el caso de las mujeres del profesorado, los numerosos y variados pañuelos de todos los tamaños, suponiendo el $43 \%$ de todas las prendas de este capítulo, seguidas, aunque en menor proporción, el $18 \%$, por las tradicionales mantillas de encaje negro, los casco de seda para las mantillas y alguna que otra manteleta, no apareciendo entre las prendas inventariadas, aunque es extraño para esta época, los sombreros como parte del atuendo femenino

Bien sean de algodón, de percal, de seda como las felpas y los crespones, o de lana como los merinos, bordados o con flecos, los pañuelos son la pieza esencial del vestir femenino, ya que aportan color a la figura, a través de los tonos vivos como los encarnados, amarillos, los estampados de flores, etc., permitiendo una variación en el vestuario sin un desembolso excesivo. Al lado de los anteriores, otras piezas del atuendo femenino inventariadas son los pañuelos de mano, los abanicos y los ridículos, pieza ésta última de tela que tomaba la forma de un bolso alargado de mano donde se guardaban las anteriores ${ }^{21}$.

Aunque la ropa interior femenina representa el 53\% del total vestuario femenino, con 241 piezas inventariadas, son pocas las variaciones que este tipo de ropa presenta. El 47,7\% son medias y calcetas, el 34\% corresponden a las enaguas, cuyas propietarias suelen tener varios pares que emplean para engordar las faldas, aunque muchas menos que las mujeres de la burguesía comercial, y casi el $13 \%$ a chambras. Las prendas nuevas, impuestas por la moda para afinar el talle femenino, como los corsés y los justillos apenas alcanzan el 5\%, inventariándose únicamente un solo pantalón interior. Mientras que la seda, la lana, el algodón y el hilo son las fibras textiles mayoritariamente empleadas en la confección de medias y de calcetas, muchas de ellas fabricadas en el propio hogar ${ }^{22}$, el percal, el cotón y el hilo eran las telas más utilizada en las enaguas y las chambras, mientras que el lienzo lo era para los justillos y corsés.

${ }^{21}$ El ridículo, tal y como lo describe Ortega Zapata, era un taleguillo de media vara de largo y una cuarta de ancho, que se hacía de tela de seda oscura o negra, con una jareta por la que pasaba un cordón, que las señoras llevaban colgando del brazo izquierdo, y donde guardaban todo tipo de artículos indispensables como los pañuelos de manos, abanicos, llaves, e incluso la tan de moda caja de rapé. Ortega Zapata, ob. cit.

${ }^{22}$ La economía doméstica resultante de fabricar las señoras medias y calcetas, se llevaba al límite del no gastar, porque en muchas casas, el hilo, primera materia, se hilaba por las mismas señoras, calculando según el grosor del mismo el destino al que se dedicaba, bien a sábanas, camisas, mantelerías, toallas, servilletas, etc. Ortega Zapata, ob. cit. 


\section{LA ROPA DE LA CASA: DEL CONFORT EN LA CAMA A LA SOBRIEDAD EN LA MESA Y EL BAÑO}

El confort y la vestimenta de la casa estaban muy equiparados con la ropa de vestir. El total de piezas inventariadas en este capítulo asciende a 1327, de las que la ropa de cama -fundas, sábanas, almohadas, colchones y jergones- suponen un porcentaje del $63,5 \%$, muy superior al que presentan las piezas de mesa con el $18,5 \%$, a las de baño con el 11,6\%, y, desde luego, al de la ropa empleada en decorar el hogar que solo es del $8,3 \%$.

Las sábanas, las almohadas y almohadones, así como las colchas y los escasos cobertores que se encuentran en las tasaciones, están confeccionados, como en otros hogares burgueses, en lienzos de hilo, finos y ordinarios. Hacia los años treinta muchas de estas piezas eran de confección casera, participando en esta labor las mujeres de la familia, que así lograban una economía en el consumo familiar. El hilo, elegido en función del destino de la pieza, se entregaba a los tejedores, muy numerosos en la ciudad, para ser luego recogida, añadiéndosele en el hogar adornos o diferentes guarniciones de percal, o puntillas y encajes de algodón ${ }^{23}$.

Las sábanas, así como los colchones y jergones, se empiezan a diferenciar por tamaños, para cama grande o de matrimonio, pequeñas y de catre. Las mantas, escasas entre la ropa de cama, al igual que los cobertores, proceden generalmente de las fábricas palentinas y suelen ser blancas o bordadas, y junto con las colchas completan el ajuar de dormir. Las colchas ganan en variedad de telas y de formas, empleándose las tradicionales telas de damasco o las de imitación como las adamascadas, los paños de seda y los tafetanes, las de lana, hasta las más livianas de algodón, especialmente las de percal -francés y catalán- en diversos colores, las de piqué blanco, y las de brillantina, lisas o adornadas, a menudo con flecos. Hacia mediados de siglo las telas que se empiezan a utilizar para fundas de colchones son, entre otras, los damascos de algodón de diverso colorido.

Si la cama es cómoda y confortable, utilizándose cada vez más la madera, en los cabeceros, y un abundante número de colchones que la visten, la ropa de mesa, aunque sea como afirma Braudel una de las manifestaciones de la civilización material ${ }^{24}$, es escasa en comparación con la anterior, estando centrada en la denominada tabla de manteles, compuesta generalmente por un mantel y varias servilletas, de confección casera muchas de ellas. Los juegos de mantelería -un mantel grande y otro más pequeño con sus correspondientes servilletas-, confeccionados por lo general en telas adamascadas, aparecen inventariados de forma más generalizada hacia el último tercio del siglo. Este modesto bagaje se

${ }^{23}$ Ortega Zapata, ob. cit.

${ }^{24}$ F. Braudel, Civilización material, economía y capitalismo. Siglos XV-XVIII. Las estructuras de lo cotidiano, Madrid, Alianza, 1984. 
compensaba con los servicios de mesa, especialmente los cubiertos de plata, considerados por los tasadores como piezas de bastante valor e incluidas dentro de las alhajas. Mientras que la vajilla es modesta, normalmente de loza, aunque hay excepciones en las que se descubren platos con el filo dorado, de china antigua o estampadas, junto a ellas se encuentran otras piezas de mayor calidad como las vinagreras de plata o de porcelana, las compoteras, las jarras de cristal y las copas talladas para las bebidas, y los vasos de cristal de diferente tamaño. Completan el confort en la mesa las chocolateras y las jícaras de porcelana china, definiendo el arraigo de ciertos gustos alimenticios tradicionales; junto al chocolate, los juegos de café que incluyen la cafetera y sus correspondientes tazas, no mencionándose ninguna tetera.

Las prendas dedicadas a la higiene son escasas, como escasas son también las zonas privadas dedicadas al aseo y a la higiene personal. Ésta suele confinarse en las alcobas y en el comedor donde se sitúan los lavamanos con sus correspondientes jarras y palanganas y los palanganeros. Para esta actividad personal son pocas las piezas inventariadas, especialmente las toallas que van siendo más numerosas hacia el último tercio del siglo, inventariándose en tres casos un total de 59 toallas, de las que 29 corresponden al profesor de Medicina Barredo, doce de calidad fina y en tela alemanisca al comerciante y también profesor en la misma facultad Pereda Repiso y dieciocho de hilo al catedrático de Lengua Griega Alonso Ortega. Abundan más, por el contrario, los paños de manos de los que normalmente cada hogar puede tener hasta media docena, aunque también en casos excepcionales se puede sobrepasar esta cifra.

Igualmente las piezas que otorgan confortabilidad a la vivienda, y que suponen el 6,6\% del consumo medio del ajuar doméstico, son poco numerosas concentrándose especialmente en las cortinas para balcones y en los visillos con que se cubren las vidrieras o cristales de las puertas, especialmente en el caso de los gabinetes, los despachos y las alcobas, lo que representa un grado de mayor intimidad dentro de la vivienda, protegiendo de las miradas inoportunas o ajenas. Normalmente las telas empleadas para este tipo de prenda del hogar suelen ser los algodones como el percal, la muselina, aunque también se usen telas más caras y de mayor calidad como el esparragón, la seda, y los damascos. En estos casos, hay una mayor ornamentación de la intimidad a través de una serie de elementos decorativos que realzan la presencia de las cortinas como las galerías y las cornisas.

\section{LA VIVIENDA: SOBRIEDAD EN EL MOBILIARIO Y EN LA ORNAMEN- TACIÓN}

Aunque desde los años cuarenta del siglo XIX la ciudad conoce un fuerte empuje económico que se reflejará en un aumento de su tejido industrial y 
comercial y en la renovación del caserío urbano, con la ampliación y apertura de nuevas calles gracias al proceso desamortizador, la sociedad vallisoletana y con ella su burguesía, incluida la élite de la cultura y la ciencia, sigue siendo una sociedad provinciana ${ }^{25}$. Una de las mayores cortapisas existentes para conocer la vivienda burguesa vallisoletana y, dentro de ella la del profesorado universitario, reside en las fuentes documentales consultadas. La mayor parte de los inventarios analizados para esta época no diferencian la organización interna del espacio habitacional, limitándose a catalogar los diversos enseres que componen el ajuar doméstico bajo una serie de apartados predeterminados de antemano en todos los casos, salvo dos excepciones en las que el inventario se realiza habitación por habitación. Esta limitación de partida, impide un acercamiento a la intimidad del hogar del profesorado y a las áreas de socialización pública y doméstica, así como al espacio dedicado al servicio doméstico y a la vida cotidiana.

La escasa información que proporcionan los inventarios en este aspecto hace, por tanto, que el conocimiento sobre la vivienda y sobre su organización interna sea algo más que incompleto. No obstante, y a pesar de las carencias que presentan, si que nos permiten situar las viviendas del profesorado en las calles más céntricas y dinámicas de la ciudad, que son por otro lado donde reside la burguesía de los negocios, del comercio y de las profesiones liberales, así como la burguesía propietaria y rentista. Y cerca del recinto universitario. A este dato se suma el que proporcionan las fuentes sobre la superficie de construcción de la vivienda que, no sólo comprende la estructura del edificio sino también el número de piso que le integran. Así, de los doce inventarios, en ocho de ellos se nos indica que los inmuebles son de tres pisos, más una parte baja a nivel de calle denominada planta o piso natural. Sobre ella, se situaban el entresuelo, el piso principal y una segunda y tercera planta. La superficie construida es pequeña, oscilando entre los 80 y los 120 metros cuadrados, superficie más reducida que la que presentan los inmuebles de otros propietarios, unidos por lazos familiares al profesorado, como el de Dolores Ibabe Osaeta, suegra del profesor de Medicina y comerciante Pereda Repiso, que alcanzaba los 201 metros cuadrados, o la del empresario comercial Cándido Díaz Higuera ${ }^{26}$ que alcanza los 813 metros cuadrados. Probablemente, como señala Serrano García, al ser un edificio de varias plantas, se reservasen para ellos la principal, pero no hay ningún dato más que permita acceder a un conocimiento mayor sobre la disposición y organización interna, ni si ésta se dispone en torno a la fachada ${ }^{27}$. Si disponemos

${ }^{25}$ Sobre el provincialismo de la sociedad de las ciudades castellanas y de sus hogares está el trabajo de Rafael Núñez Florencio, Tal como éramos. España hace un siglo, Madrid, Espasa Calpe, 1998.

${ }^{26}$ AHPV, Protocolos Notariales. Legajos 16.508 y 19.032 .

${ }^{27}$ Rafael Serrano García, ob. cit. 
de información sobre la terminación de la mayoría de estos inmuebles, que rematan en buhardillas, desvanes o solanas, incluyéndose dentro de ellos un patio interior que sirve de linde o separación con los demás edificios colindantes, y en el que se encuentra, a veces, una bodega e incluso su correspondiente lagar.

Todos los profesores son propietarios del edificio que habitan, sobre el que, en ocasiones, recaen unos réditos anuales como resultado de la compra a censo del inmueble; en otros casos lo son en razón de la sociedad de bienes conyugales, siendo la mujer la verdadera propietaria. A parte, son también dueños de otros bienes que conforman el patrimonio, cuyos mecanismos de formación han sido la herencia materna y/o paterna, la aportación a la sociedad conyugal de la dote matrimonial de la mujer o la compra, como es en este último caso la situación de los profesores de Medicina, Pereda Repiso y Pérez Martín, ambos cuñados, que ampliaron su patrimonio gracias a la dote aportada por sus respectivas mujeres. El primero sumó a la herencia paterna que le dejó dos inmuebles de tres plantas, situados en el centro de la ciudad, los que le correspondió de su mujer por bienes gananciales y como curador de sus hijos menores de edad. En total llegó a reunir como propietario seis inmuebles, aunque muchos de ellos proindiviso con sus cuñados, localizados en diversas zonas de la ciudad ${ }^{28}$.

Aunque Serrano señala que en la vivienda burguesa hay una cierta modernización, y la del profesorado participa de las características que tiene ésta, con una neta separación entre el espacio dedicado a la sociabilidad y los de uso privado, la falta de información, en nuestro caso, no nos permite vislumbrar ambos, salvo en el caso de los profesores de Medicina y de Lengua Griega, Fernández Pérez y Alonso Ortega, cuya viviendas disponían de siete y nueve habitaciones respectivamente, entre las que se encuentran el gabinete, dedicado a la privacidad cotidiana de la familia ${ }^{29}$, las salas con sus antesalas correspondientes, destinadas a la socialización mediante la visita de amigos y parientes, y donde el mobiliario está destinado a la ostentación de la situación social que la familia pretendía tener o demostrar. En esta pieza de la casa se sitúa por ejemplo el piano de mesa y la flauta de ébano del profesor Barredo Martínez, así como las diferentes mesas de juegos inventariadas al médico Pereda Repiso, al catedrático de Teología Melchor Rodríguez y al notario Nicolás López. Junto a estas piezas, se hallan asimismo sofás tapizados en telas a la moda, muebles como las cómodas, las rinconeras y los veladores fabricados o chapeados en madera de nogal, para progresivamente hacia los años setenta del siglo ser sustituido este mobiliario por otro fabricado en maderas más caras y de importación como la caoba y la madera de palo santo con que se hacen los costureros. El estrado, espacio especial-

${ }^{28}$ AHPV, Protocolos Notariales. Legajos 16.284 y 19.034 .

${ }^{29}$ J. Cruz y J. C. Sola, «El mercado madrileño y la industrialización de España», en J. Torras y B. Yun (eds.), Consumo, condiciones de vida y comercialización. Cataluña y Castilla, siglos XVII-XIX, Valladolid, Junta de Castilla y León, Consejería de Educación y Cultura, 1999. 
mente femenino ha desaparecido por completo de las viviendas del profesorado, registrándose su existencia en un solo caso, en la vivienda de la madre política del profesor de Medicina Pereda Repiso, constando esta pieza de la casa del consabido estrado, más dieciocho sillas y dos confidentes ${ }^{30}$.

El comedor es el reducto de la vida familiar diaria y en el que se reúnen una diversidad variopinta de enseres y mobiliario que comprende desde camas, lavamanos, sillas, alguna mesa, etc. Pero la mayor intimidad familiar reside en las alcobas y salas de alcoba, donde al lado de las diferentes camas y catres que se suelen encontrar en ellas, se sitúan las mesas de noche, común y numerosas en los hogares de la burguesía y más escasas en número -tan sólo se han encontrado cinco- entre los docentes, y varios tipos de baúles. Aunque la higiene y el aseo personal suelen confinarse en las alcobas, quizás, el espacio más reservado, que con el tiempo dará lugar al cuarto de baño, sea el cuarto de tocador, destinado según Serrano al arreglo personal de las mujeres de la familia y, en el que podían encontrarse la mesa de cajones con su tocador encima, un armario ropero, el correspondiente lavamanos y una sillería más o menos completa y algún confidente. Esta cantidad de mobiliario pudiera suponer que la pieza se utilizase para reunirse, durante el momento del arreglo, con el resto de los miembros femeninos de la familia, o con alguna amistad muy íntima y allegada. Muy diferente es este espacio al encontrado en casa del impresor y librero Rodríguez Manzano, situado en un hueco en el paso de una escalera y sucintamente amueblado con un lavamanos con su aljofaina de loza, una mesa pequeña de pino y decorado con pinturas religiosas ${ }^{31}$.

El despacho, también denominado cuarto de estudio, supone la consagración dentro de la vivienda de un espacio privado dedicado a la actividad intelectual. Normalmente en esta habitación se localizaban diversos muebles entre ellos la mesa de trabajo, en maderas nobles como la de nogal, encima de la que se situaba la escribanía de latón, de madera y en ocasiones de plata. Esta habitación siempre acogía el mueble dedicado a librería, que podía ser desde un estante de madera de pino con una serie de baldas, hasta un armario de dos cuerpos con puertas acristaladas, donde se disponían los libros a la vista de todo el que entrara en la habitación, familiar, amigo o cliente. Es quizás, la parte del inventario donde más meticulosidad pone el tasador tanto por el volumen de obras catalogadas como por la diversidad de materias que componen las bibliotecas del profesorado, enumerando no sólo al autor de la obra, el título de la misma, la forma de encuadernación y su valor, lo que no ocurre en los hogares de la burguesía comercial donde se habla bien de cajones conteniendo libros, o los hallados se limitan a una serie de obras de carácter eminentemente religioso ${ }^{32}$. Eso no quita

\footnotetext{
${ }^{30}$ AHPV, Protocolos Notariales. Legajo 16.508.

${ }^{31}$ AHPV, Protocolos Notariales. Legajo 16.622.

${ }^{32}$ AHPV, Protocolos Notariales. Legajos 12.003, 12.004, 16.154, 16.662 y 16.669.
} 
para que en algunos casos la biblioteca, junto con las obras que la integran, sea uno de los primeros bienes que componen el ajuar doméstico en ser vendido, posiblemente a algún librero o quizás en almoneda, por los herederos.

Sobriedad y apariencia se combinan en las viviendas familiares de los docentes universitarios, ya que frente a las maderas nobles como el nogal y las más caras como la caoba se encuentran numerosas piezas de pino, material más barato, tratadas para tener un aspecto más noble y caro. Así no es difícil encontrar en el catálogo del tasador piezas que se califican de pino laqueadas, teñidas de nogal y barnizadas para conferirlas una textura y apariencia diferente ${ }^{33}$. Por otro lado, la función de guardar la ropa sigue confiada hasta casi las postrimerías del siglo a las tradicionales arcas, en retroceso, y a los modernos baúles forrados de piel y en baqueta, claveteados, de madera, auxiliados por las perchas de madera y por los percheros, así como por los cuelga-capas que se colocan en los dormitorios y en los pasillos. Sin embargo, los armarios roperos, pieza del mobiliario más moderna, es escasa en estos domicilios, mencionándose tan sólo en cinco ocasiones, cuando, por otro lado, es más frecuente encontrarlos en los inventarios de la burguesía comercial.

Sobriedad, austeridad y un cierto lujo son tres de las características que sobresalen en la decoración de los hogares del profesorado universitario. El lujo lo señalan los numerosos pequeños objetos de plata que se encuentran en la vivienda como tarjeteros, escribanías, cajitas de rapé -afición muy desarrollada en la ciudad en esta época-, cajas de tabaco, gafas y relojes de oro y de plata de bolsillo. La sobriedad y la austeridad la indican los objetos que decoran la casa como los espejos, - de todos los tamaños- de los que se han contado tan sólo dieciséis piezas, la mayoría con un marco de madera de pino al natural, o teñidos de color nogal o forrados con papel dorado y los cuadros. De estos últimos se han encontrado en los inventarios 68 piezas, de las que más de 20 correspondían al director de la Biblioteca de Santa Cruz, Samaniego. La mayoría de ellos presentan una iconografía de tema religioso, representado a diversos santos y advocaciones de la Virgen, junto a copias de Murillo. Hay, asimismo, cuadros con historias profanas como la de Atala, la de Juan de Austria y la de Florinda encontradas entre los bienes del Director del Hospital Provincial y profesor de Medicina, Junquera, así como los cuadros con estampas del Barbero de Sevilla, heredados por el profesor Pereda Repiso. Normalmente son láminas de papel o grabados más que pinturas sobre lienzo. Este tipo de cuadro, con temática sacra o profana, es escaso, encontrándose sólo en tres ocasiones, siendo una de estas pinturas un retrato de un personaje local, perteneciente al director de la Biblioteca universitaria, Samaniego. Contrasta la escasez de lienzos con la

${ }^{33}$ Rosa $\mathrm{M}^{\mathrm{a}}$ Dávila Corona, «La cultura doméstica del profesorado vallisoletano», en Las universidades Hispánicas. De la Monarquía de los Austrias al Centralismo Liberal, Valladolid, Junta de Castilla y León y Ediciones Universidad de Salamanca, 2000. 
mayor abundancia que presentan los inventarios de otros miembros de las profesiones liberales como el notario Nicolás López, en posesión de diecisiete cuadros de los que más de la mitad eran pintura al óleo sobre lienzo, junto a cuadros de cobre repujado y plateado, así como una escultura realizada en marfil y enmarcada en madera de olivo ${ }^{34}$.

Junto a los cuadros, láminas y grabados, se registran también una serie de adornos para la pared muy al gusto de la moda del momento ${ }^{35}$ como son las labores femeninas realizadas dentro del hogar, cuyos temas son diversos como los abecedarios, bordados en seda, figuras, paisajes e incluso imágenes religiosas, protegidos por un cristal, de la misma forma y manera que los cuadros de láminas, representando al tiempo que una labor primorosamente ejecutada, el sentimiento afectivo, a través de la dedicatoria que llevan bordada, por un miembro de la familia, bien el padre o la madre.

Llama poderosamente por su escasez en los inventarios la falta de objetos empleados para la iluminación de la vivienda. Así, de los modernos quinqués sólo se cuentan en los doce inventarios cuatro ejemplares, lo que por otro lado no resulta demasiado sorprendente ya que tampoco abundan en los hogares del resto de la burguesía ${ }^{36}$. La iluminación sigue los patrones tradicionales empleando para ello las consabidas velas de esperma y de abeja -las más caras-, y las más baratas de sebo, así como los aparatos donde colocarlas como candeleros, velones, lámparas de latón o de metal. Es sorprendente que, a pesar de que desde los años cincuenta se halle instalada en la ciudad una fábrica de gas y empiecen a ser corrientes los aparatos que emplean este tipo de iluminación, no haya mención alguna en los inventarios analizados del profesorado, pero tampoco en el resto de la burguesía.

La medida del tiempo es otra de las carencias que podemos anotar dentro de los inventarios del profesorado. Mientras que los del resto de la burguesía -sobre todo comercial y de profesiones liberales- aparecen los relojes de diversas formas y tamaños, especialmente los de pared y los de sobremesa de fabricación inglesa, tan sólo en cuatro de los doce inventarios de la clase docente aparece este tipo de reloj ${ }^{37}$. En su defecto, casi todos son dueños de relojes de bolsillo bien de plata -en la mayoría de los casos- bien de oro. Es difícil, por tanto, interpretar esta carencia, en una etapa en que el reloj se encuentra difundido por el resto de los hogares burgueses, existiendo además establecimientos especializados que se

${ }^{34}$ AHPV, Protocolos Notariales. Legajos 15.882, 16.622 y 19.034 .

${ }^{35}$ Agustín Figueroa, Modas y modos de cien años, Madrid, Aguilar, 1966.

${ }^{36}$ En la casa del notario Nicolás López entre los diversos utensilios empleados para la iluminación del hogar, como candeleros, velones de latón con pantalla, palmatoria, lámpara solar, etc., se encuentran dos quinqués de metal dorado, muy usados, mientras que en la del comerciante y fabricante Díaz Higuera hay otros dos barnizados.

${ }^{37}$ AHPV, Protocolos Notariales. Legajo 16.622. 
anuncian en el periódico local, con ofertas de todo tipo y al alcance de muchos bolsillos.

\section{A MODO DE CONCLUSIÓN}

Los inventarios post mortem son una de las vías fundamentales, aunque con limitaciones, para aproximarnos al mundo de la cultura material del profesorado vallisoletano en el siglo XIX. Las variaciones en el criterio de los peritos al tasar el ajuar doméstico y la prioridad dada, por encima de su descripción, al valor monetario de las prendas de vestir y de la casa, del mobiliario y demás enseres del ajuar de cara al reparto de la herencia, no permiten un acercamiento fiel a la imagen personal, ni tampoco posibilitan un conocimiento del interior y disposición de la vivienda familiar. Al prescindir, en este último caso, de la enumeración de las habitaciones y de los enseres y mobiliario que las ocupaban, limitándose a agruparles en grandes apartados previamente determinados, impiden, en la mayoría de los casos, un conocimiento mayor de la distribución del interior de la vivienda y de los diferentes espacios dedicados a la socialización, a la intimidad familiar y a la vida en común.

Si la imagen académica del profesorado quedó fijada mediante las diversas disposiciones legislativas que se dieron en los años cuarenta y cincuenta del siglo XIX, la imagen personal que proporcionan los inventarios es la de un miembro más de la burguesía provinciana, tanto en la adopción de sus valores -honestidad, decoro, discreción, laboriosidad-, como en su ideología conservadora, traduciéndose en una imagen pública en armonía con los valores anteriores. La democratización de la indumentaria masculina del docente universitario se evidencia en el abandono de las antiguas prendas usadas a principios de siglo como las chupas, los jubones y las casacas, sustituidas por otras más modernas como el traje en el que la levita será la prenda principal, en consonancia con los valores estéticos que detenta la burguesía de la que forman parte. El resultado es una figura austera, sobria, con el empleo de colores oscuros, sólo iluminada por algún toque de color que proporcionan prendas como los chalecos confeccionados con telas de calidad como la seda y el terciopelo, los corbatines y los pañuelos. La apariencia es otra de las características de la imagen del profesorado, realzada por el empleo de numerosas piezas postizas, como los cuellos, los puños y los camisolines, que puestas sobre prendas de vestir como las camisas, en su mayoría calificadas como usadas, les conferían el aspecto de ser nuevas.

Los cambios en el guardarropa femenino no son tan evidentes como en el del profesorado, y aunque es cierto que han desaparecido también una serie de prendas tradicionales como los guardapiés o las basquiñas sustituidas por el traje, de difícil valoración al no existir descripción alguna de las piezas que lo integra- 
ban, sin embargo aún no se han incorporado prendas más modernas como las que ya usa la burguesía como las faldas y los abrigos.

Si la imagen unida a la apariencia personal fue importante en el profesorado y en su familia, suponiendo como media dentro del ajuar doméstico del $20,5 \%$, el confort de la cama y de la casa se mantuvo en la misma línea. La ropa de cama con su $63,5 \%$ sobre el resto de la ropa de casa, indica la importancia dedicada a la parcela de la intimidad y del descanso, y aunque muchas de las piezas sean en un principio de confección casera, esto no impide que vayan adornadas con guarniciones y puntillas, empezando a diferenciarse en su empleo para cama de matrimonio, pequeñas o de catre. La intimidad se refuerza con la instalación de cortinas en los balcones de las salas, de los gabinetes y de los despachos para apartar las miradas indiscretas o ajenas, mientras que las puertas de cristales de las alcobas se cubren con visillos para hacer este espacio más íntimo.

La cama se ennoblece con la aparición de cabeceros de madera noble como el nogal, lo mismo que los muebles que se sitúan en las diversas habitaciones como cómodas, rinconeras y veladores, e incluso en los espacios de sociabilidad se localizan piezas modernas como las mesas de juego, los pianos, etc., que enfatizan la posición social de la familia, fabricados en maderas caras como la caoba, aunque esto no impide la existencia al mismo tiempo de un mobiliario más barato -en madera de pino-, pero tratado con tintes, pinturas y barnices para darle una apariencia de mayor calidad. Y sin embargo, en los espacios más íntimos como las alcobas siguen dominando los baúles como medio de guardar la ropa, siendo casi una rareza la aparición de los armarios y de otros objetos modernos para la iluminación como los quinqués, empleándose la iluminación tradicional a base de velas.

Esta misma tendencia a combinar la apariencia y el confort se aprecia en la ropa de mesa, que representa el $18,5 \%$ del total de las ropas de casa inventariadas, y en las que las piezas más significativas, a mediados de siglo, siguen siendo las tablas de manteles, ya que los juegos de mantelerías -un mantel grande, otro más pequeños y sus correspondientes juegos de servilletas- no serán significativos más que a partir del último tercio del siglo. Este modesto bagaje se compensaba con el lujo existente en los servicios de mesa, especialmente -no faltaba en ningún hogar del docente- los cubiertos de plata, y otras piezas más caras de cristal o porcelana, aunque la vajilla de mesa fuera frecuentemente de loza, no faltaban los platos con filos dorados o de china antigua. Completan el confort en la mesa las chocolateras y las jícaras de porcelana china, definiendo el arraigo de ciertos gustos alimenticios tradicionales. 